\title{
THEORY OF MIND DEVELOPMENT \\ IN HEARING IMPAIRED CHILDREN ${ }^{1}$
}

\author{
Joanna Kossewska
}

\section{Key words}

Deafness, theory of mind, communication deprivation, educational system.

Theory of mind has been viewed as fundamental for our understanding of the social world. It helps us to make sense of the complex patterns of many social relationships such as the acts of deception, interpersonal conflicts and negotiations. It animates our sense of humour so it is also fundamental for our appreciation of cultural acquisition, such as literature, drama or film.

Since the first study in the field of theory of mind in the deaf by Peterson and Siegal (1995) it has been discovered that the majority of the profoundly deaf failed the false belief test. However, more recent research indicates that deaf children are rather not impaired in theory of mind development process but just delayed in developing theory of mind. Nevertheless, that developmental deficit is quite serious when compared to hearing children - deaf children aged 5-12 years solve tests focused on theories of mind better than 3-year-olds but not as well as 4 year-olds, although the background mechanism itself is not damaged (Courtin, 2000).

This article describes factors which influence that theory of mind developmental delay. It presents the context of language as well as communication deprivation within the family and educational system.

\section{Introduction}

Human beings have a deep-seated mental competence to facinate with other people; both significant others as well as strangers and to predict and explain their behavior. The process of explanation of other people's behavior is based on understanding mental states, such as beliefs, desires and intentions of those people. Individuals understand the behavior of others in terms of their beliefs about the world.

\footnotetext{
${ }^{1}$ The paper was supported by grant from the Polish Ministry of Science and Higher Education.
} 
The ability of attempting to make sense of the mental life of other people is called "Theory of Mind" (ToM). The term "Theory of Mind" was coined by David Premack and Guy Woodruff (1978) who tested a chimpanzee's ability to predict a person's behavior by means of mental state attribution. In a study, four juvenile chimpanzees learned to indicate two opaque containers with food to a naive human trainer. After learning to do this, two different types of trainers were introduced: a cooperative trainer acted as he had done before (attempting to locate the hidden food and when he found it giving it to the subject), and a competitive trainer (attempting to locate the food, but when he found it he kept it and ate it himself). It was found that two of the chimpanzees (50\%) had learned to indicate the incorrect container for the competitive trainer. Theory of mind seems to be basic if primates are skilled in it. However, the human version of primate social cognition has some special qualities related to complex cultural life, in which individuals live in the context of their beliefs about other people's beliefs.

Theory of mind has been defined as the ability to think about other people's mental states and form theories of how they think. Mental states are abstract entities whose relations to the world are not immediately transparent, particularly when the mental states do not correspond with reality so it has been suggested that exposure to opportunities for reflecting on the discrepancy between mental states and reality is important for theory-of-mind development (Brown, Donelan-McCall, Dunn, 1996).

The theory of mind seems to be a core mechanism of human social life because its lack or disorder creates major barriers to communication and closeness. These barriers often make those closest to the individual feel a lack of sympathy, whether real or perceived, towards the individual. In the many years since the paper by Premack and Woodruff (1978) was first published the most extensive research has been done in the field of developmental psychology, where scientists have investigated what human children know about the minds of others. The most important problems in the theory of mind field of interests are related to: firstly, predictor of theory of mind development, secondly, its neurological basis as well as the process of its development, thirdly, the conditions of its proper development and last but not least, the delay or disorder in theory of mind development in atypical population. 


\section{Theory of mind - its development and assessment}

After the publication by Premack and Woodruff (1978) it was suggested that children could be tested to see if they have a theory of mind by giving them a so-called false belief task. This is a test to see whether a child will act on a knowingly incorrect belief, or be aware that a second person who is not in possession of a certain piece of information may act incorrectly. There are now two main versions of the false-belief task: Unexpected Location task and Unexpected Content task.

In the Unexpected Location task, a story character places an object (e.g. chocolate) in one location. While he or she is away, the object will be transferred into a new location. The child who is tested has seen the transference, but has to figure out that the story character will look for the object where he or she falsely believes it is located, and not where it actually is. Thus, the child is asked a test question "Where will [Maxi] look for the object [chocolate]?" accompanied by two control questions, "Where did [Maxi] first put the object [chocolate]" and "Where is the object [chocolate] now?" (Wimmer and Perner,1983).

Like adults, typically developing 4-year-olds most commonly judge correctly that the figure will look where the object was located previously. These correct judgments are widely regarded as good evidence that the participant considers figure's behavior to be determined by her (false) belief. In contrast, 3-yearolds commonly err by judging that the figure will look in the new location.

In the Unexpected Content task named also the Deceptive Box task, the child is shown a familiar candy box (or Smarties tube) and is asked what he or she thinks is inside. Having been shown that something other than candy (or chocolate) is inside, the child is then asked what someone else who has not looked inside would think the box contains. Again the child has to understand that others behave according to their own beliefs about reality, even when these are inaccurate. To pass the task the child also has to correctly answer a question about his or her own false belief, "When I first asked you, before we looked inside, what you thought was in the box?" and to correctly answer the question "What is really in the box?" (Perner et al., 1987). These classic and well known procedures have been frequently used in many studies with various modifications.

Three-year-old children almost always fail theory of mind tasks. In the Maxi task they say that Maxi will look in the new location for his chocolate rather than the original location in which he placed it and where he would expect it to be. In the Smarties task three-year-olds say that another child will expect 
there to be pencils in the tube. Four- and five-year-olds, however, normally pass both the unexpected transfer and the deceptive box tasks indicating that they are able to distinguish between their own knowledge about the real location and the content and that of another person who was not aware of the transfer. Therefore, Wimmer and Perner argued that children exhibit an understanding of false belief at 4-5 years of age.

The third well known theory of mind task is Appearance-Reality task (Flavell, Flavell, and Green 1983). This task involves showing the child an object (e.g. a Charlie Brown doll) and then changing the object's appearance (e.g. covering the doll with a piece of white fabric with eye and mouth holes cut out; creating the appearance of a ghost). With the new appearance in sight, the child is asked two questions. One question is known as the appearance question: "When you look at this object with your eyes right now, what does it look like?" There is also a reality question: "What is this really and truly? Is it really and truly a ghost or really and truly Charlie Brown?" To succeed on appearance-reality tasks, children must realize that an object's appearance might conflict with reality. For example, a white object viewed through a blue colored filter will appear blue, even though it is actually white. Although nearly all typically developed children achieve success on false belief tasks at approximately the same age, there are individual differences in that achievement, with some children succeeding at slightly younger ages than others.

Research on ToM has produced various theories on the nature of ToM development. One of them is a neurological theory of ToM, which explains neuorological mechanisms underlying the development of ToM, due to many examinations with the use of PET, the neuroimaging method of human brain functions. ToM depends on a specific brain mechanism related to significantly increased regional cerebral blood flow in the following regions: the temporal poles bilaterally, the left superior temporal gyrus, temporo-parietal junction and the posterior cingulate cortex (Fletcher et al., 1995, Saxe and Kanwisher, 2003). A second theory posits that false-belief understanding develops out of other capacities that mature during the infancy. For example, pretend play (Leslie, 1987) and shared attention (Baron-Cohen, 1995) may be skills that precede ToM abilities. There are some specific prerequisites to theory of mind. Firstly, a child must understand that individuals can have desires what may be assessed by joint attention and protodeclarative pointing, secondly, they use pretend play skills and metarepresentation, and thirdly, they begin to use mental state terms such as "think," "know," "want," and "remember". A third theory postulates 
that the development of ToM is influenced by exposure to conversation about mental states. According to this theory, there is the relationship between verbal ability and ToM in normally developing children (Perner, Ruffman, \& Leekman, 1994, Jenkins \& Astington, 1996, Białecka-Pikul, 2002). However, the communication difficulties may prevent some children from being able to successfully converse with others. DeVilliers and deVilliers (2000) have emphasised that performance on false belief tasks depends on understanding complex language and that individual differences may reflect differences in language ability. Several studies have found that children with better language skills perform better on false belief tasks (egg. Astington, Jenkins, 1999). The idea that the accurate use of the linguistic terms describing mental states, such as "think", "know" and "remember", requires that they be understood. If a child does not understand what these words mean, then they are likely to fail false belief tasks.

Some researchers have pointed out that family background may also account for some differences. It was found that children with older brothers or sisters succeed in theory of mind tasks earlier than only children or those with a younger sibling (Ruffman et al 1998). Older siblings provide opportunities through play and discussion for younger children to learn about the mental states of others. Parental occupational class and the level of mother's education may also be good predictors of theory of mind development, because they influence language ability and emotional understanding within family (Cutting and Dunn 1999).

\section{Theory of mind in the field of exceptional psychology}

within the last twenty years scientists have also tried to investigate theory of mind development in children with pervasive developmental disorders and different impairments. Since prime publication by Baron-Cohen el. al.1985 numerous populations have been observed to fail tests of theory of mind, such as false belief tasks. Autistic groups and children with specific sensory impairments have also been compared.

In 1985, Baron-Cohen, Leslie and Frith were the first to ask the question of whether autistic children have a theory of mind (Baron-Cohen, Leslie, \& Frith, 1985). Autism is a pervasive developmental disorder that is characterized by qualitative impairment in social interaction and communication, as well as restricted repetitive and stereotyped patterns of behavior, interests and activities (APA, 2000). Children with autism frequently exhibit atypical language development; they may have difficulties using language related to the emotional states 
of other people. It was found that children with autism have neither a theory of their own mind nor a theory of other people's minds. These first findings by Baron-Cohen were fundamental to our knowledge and the way of understanding the behavioral problems of autistic persons. However, in the face of thirty years of research in the field of the deficits in theory of mind in autism the strong negative answer should be lessened. To substantiate the claim that theory of mind is a core deficit in autism, three requirements must be met: individuals with autism must universally fail tests of theory of mind; theory of mind must be innate; and theory of mind must depend on a specific neural mechanism.

McAlpine and Moore (1995) studied theory of mind in blind children and found that blind children were somewhat delayed in passing a false-belief task, though this may have been in part due to the greater information- processing demands of such a task for children who cannot use visual cues.. Although blind children are not impaired in verbal communication, they are impaired in some forms of nonverbal communication, and in particular, are not able to detect eye direction: a skill that is usually seen as important, though not absolutely essential, for the development of shared attention (Baron-Cohen, 1993, 1994). The latest findings of the research into the neurological basis of theory of mind by Bendy el al (2009) showed that despite different developmental experiences congenitally blind people have a typical ToM network. The authors concluded that the development of neural mechanisms for ToM depends on innate factors and on experiences represented at an abstract level, amodally. This finding would have great importance into other field of interests, however, researchers are still looking for exceptionality in theory of mind development by hearing impaired people. Therefore the following groups were also subject to studies: deaf children (Peterson \& Siegal, 1995, Courtin, 2000, Lundy 2002), non-autistic children and adolescents with intellectual disability (Benson, Abbeduto, Short, Nuccio, \& Maas, 1993), children with Cerebral Palsy (Dahlgreen, et al., 2002, Falkman, 2005), children with Down's Syndrome (Zelazo, Burack, Benedetto \& Frye, 1996), Parkinson's patients (Saltzman, Strauss, Hunter, \& Archibald, 2000), frontal lobe patients (Rowe, Bullock, Polkey, \& Morris, 2001), and, rather curiously, children with a specific language impairment (Miller, 2001), as well as children with Williams syndrome and Pader-Willi syndrome (Karmiloff-Smith, et al, 1995; Sullivan, Tager-Flusberg, 1999; Tager-Flusberg, Sullivan, 2000).

The findings mentioned hereinbefore have been highly influential on the field of developmental psychology and have implications for study of theory of mind in hearing impaired children. 


\section{Theory of mind in hearing impaired children}

Why does sensory impairment influence specific problems within theory of mind development? What are the predictors of normal development in children with hearing impairment? Answers to these questions could give real support to parents and help the families of children with hearing impairments to deal with developmental delay, as well as to stimulate social development of their children.

The first study in the field of theory of mind in the deaf by Peterson and Siegal (1995) revealed that $65 \%$ of profoundly deaf Australian children aged 8-13 using Auslan (Australian sign language) to communicate failed the false belief test. They reported that only $35 \%$ of them passed a version of the classic "Sally- Anne" task. The level of performance shown by deaf children did not differ significantly from that reported for autistic children of a comparable (nonverbal) mental age. These results were replicated in a later comparison of deaf and autistic children across a wider age range using a wider range of tests (Peterson \& Siegal, 1997, 1999, 2000).

More recent research indicates that deaf children are not impaired in theory of mind development but just delayed in this process. However, that delay is quite serious compared to hearing children, in some cases not reliably understanding false belief until early adolescence. Deaf children aged 5-12 years solve tests focused on theories of mind better than 3-year-olds but not as well as 4 year-olds, although the background mechanism itself is not damaged and the problem is not related to hearing impairment per se but rather to some aspects of language context (Courtin, 2000; Lundy, 2002).

\section{Early exposure to language}

The role of language has often been perceived as fundamental to theory of mind development in hearing children, which was described previously (Astington \& Jenkins, 1999; de Villiers \& de Villiers, 2000; Biłecka-Pikul, 2002), thus it should also be important to the deaf. The strong evidence for such a general conclusion was found in researches comparing the false beliefs in deaf children who are native signers of a sign language (usually the second generation of deaf children who have been raised by signing deaf parents) and late signers - deaf children of hearing parents (often learning sign language only once at school). Serious delay in theory of mind development was first argued within the theory of limited early exposure to language. It seems that many deaf children will be delayed in gaining conversational access to information about the intangible thoughts and feelings of others. According to Peterson and Siegal (1995, 2000), 
the primary cause of a delayed development of ToM is the lack of access to conversations.

It is obvious that the deaf children group is not homogeneous because more than $90 \%$ of deaf children have hearing parents. So it might be concluded that theory of mind developmental delay occurred in deaf children of hearing parents (late signers).

Studies composed of different tasks show interesting, however differential results due to the fact that in many studies late signers are older than the compared hearing children, when typically pass false belief tasks. So it is difficult to determine how native signers compare with hearing peers in terms of development of false belief understanding if different age groups are taken into account. Peterson and Siegal (2000) summarised the results of 11 separate investigations from different cultures and educational systems involving profoundly deaf children and false belief tests and found consistent support for the finding that late signers are seriously delayed in acquiring theory of mind, whereas the delay amongst native signers was not so marked. The value of the child's social and emotional development depends on visual and tactile communication techniques of interacting developing naturally between a deaf child and a deaf parent.

Peterson et. al. (2005) have shown that only a third of the late-signers aged 5.5-13.2 years could pass a false belief task, whereas $60 \%$ of deaf adolescents from hearing families could not understand another person's false beliefs. It ought to be emphasized, however, that the findings of different scientists from the studies comparing different age groups are divergent, depending on age, and depict smaller developmental delays in ToM development. According to the study by Moeller and Schick (2006) deaf children pass false belief tasks at younger ages (6- and 7-year-olds: $63 \%$ passed; 8- and 9-year-olds: $75 \%$ ) and native signers perform significantly better on ToM tasks than their late signers peers. The only study so far to compare native signers with their hearing peers at the same age was conducted by Courtin (2000), who studied ToM skills in a both native and late signers. It was discovered that the 5-and half-years-old native signers outperformed the 7-year-old late signers, regardless of whether the latter were learning sign language or spoken French. And what is more significant, native signers were significantly better on the false belief tasks than a control group of hearing peers. This results show an enhanced performance in deaf children learning sign language because most sign languages (if not all) have grammatical structures to indicate the space. All of linguists divided signs 
into several phonemic distinctive features: hand shape, palm orientation, hand movement, hand location, as well as non-manual features such as facial expression, posture, and mouthing which are going on within space. Therefore, taking one's own or somebody else's perspective within the visual space is a basic element of the sign language grammar. Because of visual aspects of sign language, deaf children learning sign language may be particularly advantaged when taking perspective of others as well as learning concepts about mental states.

As in the previous studies Schick et al. 2007 found that the development in the field of understanding false beliefs and konwledge about mental states was delayed in case of deaf children of hearing parents, irrespective of a dominant language of an educational system (schools with spoken English or ALS). In contrast, native signers performed with no significant difference to the hearing children on any of the ToM tasks, either verbal or low verbal. This means that the deaf children with hearing parents are not delayed in ToM because of their deafness per se. Early access to an equivalent language in another medium, namely ASL, is just as effective for communicating ToM, as demonstrated by the native signers performance. This study showed that early exposure to sign language is an important factor of ToM development but, in contrast to a finding by Courtin (2000), does not show that the native signers are advantaged in their ToM development compared with their hearing peers, providing there was no evidence that sign language was facilitative over spoken language.

Hearing families that experience difficulty in communication with deaf children about everyday routines also suffer extreme difficulty talking about thoughts, beliefs and intentions. As a result, language-delayed deaf children miss out on references to abstract, unseen entities such as mental states, and have fewer raw materials to develop ToM concepts. Deaf children do not have any special problems with social interaction other than that imposed by delayed language skills, unlike children with autism, who have also been shown to be significantly delayed in ToM development (Peterson \& Siegal, 2000).

\section{Common engagement}

If a child is not able to communicate with others by means of a communication channel he or she understands, it limits the child's background of the psychical safety feeling construction, which is the basis of the ability to create his/her identity (Zalewska, 1998). The stress by a hearing mother of a deaf child makes her experience herself as also being deaf in contact with her child because her communicating skills are not adequate. As a result, many deaf 
children have access to neither spontaneous spoken conversations nor nonverbal behavioural dialogues. The early behavioral dialogue is fundamental for developing imitation and cooperative skills as the basis of all different learning skills. During a behavioral dialogue, which constitutes a first step towards the development of episodes of common engagement, a mother gives all her love and care to her child, which provides the child with the feeling of security and helps them establish a secure attachement. It was found in hearing toddlers that the theory of mind development during a preschool stage takes place as toddlers attend to both social-emotional and symbolic aspects of shared events. When controlling for language comprehension at 30 months, higher preschool false belief scores were associated with more time spent in both coordinated joint engagement with a caregiver in an ealier toodlerhood and in a symbol-infused joint engagement in a later toddlerhood (Nelson, Adamson, Bakeman, 2008). Tomasello et al (2005) describe three levels of episodes of engagement predictable for social cognition. First is Dyadic engagement called also protoconversations (before $9 \mathrm{~m}$ ). These are social interactions in which the adult and infant look, touch, smile, and vocalize toward each other in turn-taking sequences based on sharing behavior and emotions. Second is Triadic engagement based on sharing goals and perception $(9-12 \mathrm{~m}$.). The child interacts together with a goal-directed agent toward some shared goal. In doing this, both interactants perceptually monitor the goal-directed behavior and perceptions of the partner. These are activities such as giving and taking objects, rolling a ball back and forth, building a block tower together, putting away toys together, "pretend" games of eating or drinking, "reading" books, and pointing-and-naming games. During these activities, infants' looking becomes coordinated with that of the other person triadically toward the relevant outside objects as well. Third is Collaborative engagement: the stage of joint intentions and attention (12-15 m). The child interacts with an intentional agent toward some shared goal and with coordinated action plans as manifest in a joint intention - and with joint attention (mutual knowledge) as well. Tomasello argues that humans' cooperative communication emerged first in the natural gestures of pointing and pantomiming. Conventional communication, first gestural and then vocal, evolved only after humans already possessed these natural gestures and their shared intentionality infrastructure along with skills of cultural learning for creating and passing along jointly understood communicative conventions. Prelingually deaf children, being born unable to hear but growing up in an environment rich with episodes of engagement at all three mentioned above levels, may be free 
of communication difficulties. Deaf children born to signing deaf parents can develop natural and fluent communication skills as well as ToM (Marschark, et al., 2000; Moeller, 2002; Gray \& Hosie, 1996). Deaf children of hearing parents usually grow up in the environment poor in stimulations and with low impact of engagement, and they often are treated as objects of speech therapy, which is connected with the more authoritarian way of communication that seems to focus on parental own wishes rather than the subject of personal dialogue in which the child' feelings and needs are respected. In such a situation, deaf children of hearing parents are usually deprived of any possibilities as well as motivation to explain their own needs and take their own, independent decisions. What is more, they are often forced to communicate verbally with others. Such a contact and an early communication experience result in deaf children's tendency to use repetitions and arguments that do not provide new information to their conversation partners and in their decreased ability to take the perspective of others.

In contrast to such a developmental pattern, deaf children of deaf parents who use a sign language as native (native signers) will not be at all delayed in ToM. Native signers performed the same as hearing controls at ages 4, 5, and 6 years on both verbal and low verbal ToM tasks (Courtin, 2000; Peterson \& Siegel, 1997, 1999; Woolfe et al, 2002).

\section{Language acquisition}

Second context of language might be pointed out as language acquisition. Many studies of deaf children suggest some causal role for language acquisition in the development of an understanding of false beliefs (P. de Villiers, 2005). A subgroup of native signers are exposed to a full language from birth in the form of a natural sign language, so their language acquisition follows the normal timetable and have demonstrated similar developmental pattern in language acquisition to hearing peers (Schick, 2003). In contrast, many late signers have significantly delayed language acquisition, although they have age-appropriate non-verbal intelligence and active sociability. Language delayed deaf children also show a significant delay in ToM development.

Lundy (2002) used Language Proficiency Profile and found that age was the most significant predictor of verbal false-belief task performance. Language skills of 34 deaf and hard of hearing children, ages 5-10, were found less significant for the children's theory of mind development then age. More recent studies showed that grammatical skills of deaf children were highly correlated 
with false belief measures (Moeller and Schick 2006). The children's own language scores predicted a small but significant $14 \%$ of the variance in their ToM scores, however, both age and maternal language were highly correlated with the children's ToM performance. Significant predictors of ToM might be also both vocabulary comprehension and syntax production (de Villiers and Pyers 2002) It was found that there were significant predictors of 23 oral deaf children's performance on both verbal and nonverbal tests of false belief tasks, even when the effects of age, nonverbal IQ, and hearing loss were controlled. However, the language acquisition is very important for theory of mind development, it was also found, when comparing late signers to native signers in terms of language age that they are still significantly delayed in their false belief reasoning (Woolfe et al., 2002). This might be interpreted as the background of theory of mind development by deaf children is very complex and conditioned by numerous factors.

\section{Significant others - the mother and siblings}

Both aspects of language context basis for theory of mind development in deaf children which were mentioned hereinabove are related to the common mode of communication within family. Moeller and Schrick (2006) has found that mother's signed use of mental state expressions (desires and cognitions) in describing events to their signing deaf children is predictive of the children's ToM reasoning, independent of the children's own language skills. It means that a deaf mother spontaneously stimulates theory of mind development of her deaf child, even though his or her language competences are not highly developed. When engaging in conversations about mental state, a mother's signing skill impacts the frequency and diversity of these discussions.

Several studies have found that relatively few hearing parents achieve sufficient proficiency in manual communication to converse fluently with their deaf children about imaginary or unobservable objects as well as abstract concepts (Marschark, 1993). Hearing mother's use of sign language to name significant mental states has a crucial influence on the development of ToM in deaf children, irrespective of the fact if the mother herself is a native signer or not. Thus, a training of hearing mothers of deaf children in the first generation in the field of basic command of the signs of sign language that describe mental states seems to be of paramount importance. As a mother is one of the most important significant others in early childhood as well the best model of language development, she exerts a very important impact on the value of her child's 
social interaction and ToM development. Results (Moeller, Schrick, 2006) showed that maternal sign proficiency was correlated with a child's language, false belief, and mothers' talk about the mind. Frequency of mothers' mental state talk was significantly related to ToM, after controlling for the effects of language. The frequency of maternal mental state input was influenced by the level of maternal sign skill.

Although initiating an interaction and communication with a deaf child often motivates a hearing mother to learn sign language, she is in many cases unable to communicate mental states to her child. Moeller and Schick (2006) found that hearing mothers varied in their ability to use signs for mental state terms and that the mothers' ability and willingness to talk about the mind was correlated with their own child's ability to pass false belief tasks.

Deaf children of hearing mothers who use sign language in communication about mental states demonstrated only slight ToM delays in comparison to other studies.

Siblings of deaf children, both deaf and hearing, might also play an important role in theory of mind development. It was found that the quality of the sibling relationship predicted ToM reasoning over and above the age of the children and the effectiveness of conversation about the physical world (Woolfe, 2003). Siblings of deaf children can provide a positive environment in which children are exposed to talk about mental states that alerts them to the possibility that beliefs may differ from reality. Participating with sibilings in pretend plays, deaf children engage in numerous communicative situations that require describing mental states and reality. The children also might have an opportunity to confront the reality and false beliefs of another person.

\section{Schooling system}

Theory of mind development might also be related to an educational system. School environment also seems to be an important factor of ToM development in deaf children. They usually are taught in three different type of schooling: segregated, mainstream or regular schools for the hearing. These types differ not only in the impact of social and cognitive integration but, what is more influencial, in the mode of communication. Schools varied in the level of oral vs. sing language to be used.

Children educated by means of total communication, bilingual communication and oral language were compared (Courtin, 2000, Peterson, Siegal 1999). Deaf children of hearing parents are delayed in the development of theories of 
mind no matter what communication pattern has been adopted in their education, which means that the delay is not specific or related to the way of teaching. The findings showed that education in a TC classroom where sign was used along with speech neither enhanced nor detracted from ToM development, relative to mainstream schooling (Peterson, 2004). Some hearing parents of deaf children opt for a purely oral approach to family communication and for mainstream or regular oral-only schooling. Language development is generally delayed in orally educated profoundly deaf children who use conventional hearing aids (Svirsky, Robbins, Iler-Kirk, Pisoni, \& Miyamoto, 2000) so they also would have delay in ToM. Along with delayed language, restrictions upon the oral deaf child's opportunities to exchange information about thoughts, feelings, or intentions with hearing parents, peers and siblings may curtail ToM development. Orally-taught deaf child not exposed to sign language experience the limited speech, vocabulary and syntax typically present at age 4 years however this level is not sufficient to support elaborate mind-talk, especially reference to others' beliefs. Consequently, if language and early family conversation are critical factors for ToM development, orally educated deaf children with hearing aids should be delayed in mastering concepts of false belief.

That might be the argument for bilingual education (Singleton et al., 1998) which assumes that sign language is the primary basis of deaf children's development both in cognitive and emotional-social aspects. Its good frame for the development of the second language development, which for the deaf means oral national language used by the hearing majority.

There is also evidence that teachers of the deaf, as well as hearing teachers of hearing children, vary a great deal in how much they talk about the mind. Given that many deaf children often have a limited range of social partners who can they communicate fluently with, restricted input is a serious issue for many children.

The education of deaf children living in an integrated environment needs to look beyond functional communication and academic skills and ensure there is also a focus on more complex aspects of social and emotional understanding and development.

Theory of mind skills could be trained both in autistic children (Wellman, et. al. 2002) and the deaf (Cerruto, 1999). In the study by Cerruto (1999) it was hypothesized that children who are deaf would demonstrate delayed development of theory of mind on a pretest. However, two sessions of training would improve their belief tasks performance in a posttest. Training study was 
organized for a group of 38 children, between the ages of 5 and 13. The children participated in control and belief training groups and received two sessions spanning two weeks. A two-week and subsequent four-week pretest, posttest and follow-up task were administered. A simple false belief pretest task results showed that firstly, the vast majority of children who are deaf (77 \%) failed that task, secondly, a significant relationship between age and belief task performance existed, thirdly, an insignificant relationship between IQ and belief task performance was found, and fourthly, an insignificant relationship between gender and belief pretest performance was found as well.

In general, the results of the study suggest that two belief training sessions spanning two weeks had an effect on deaf children's performance on false belief tasks. The results of a t-test indicated that significant differences were found between the theory of mind training group and the control one on posttest scores measured on total, self, and other scores. More detailed results showed that the gender was not the significant factor in theory of mind improvement after training. This early bird study suggested that future research should be done to predict the transfer of training results into different objects as well as secondary level of beliefs.

\section{Conclusion}

Many studies found that deaf children represent a delay in theory of mind development, however, the performance of false believe tasks by native signers (deaf children of deaf parents) is much better then late signers (deaf children of hearing parents). It is argued that deaf children with language delay are significantly delayed in their mastery of false-belief reasoning. Language may, therefore, perform two important roles: it can be a common code of communication, which during an interaction strengthens communicative competences of deaf children and it can facilitate establishing social contacts with significant others.. Sharing common attention during the episodes of engagement stimulates the ability to take perspective of others and to communicate about mental states. Significant others (mother and siblings) are very important figures in this process.

\section{References}

AMERICAN PSYCHIATRIC ASSOCIATION (2000). Pervasive developmental disorders. In Diagnostic and statistical manual of mental disorders (Fourth 
edition-text revision (DSM-IV-TR). Washington, DC: American Psychiatric Association, pp. 69-70.

ASTINGTON, J. W., \& JENKINS, J. M. (1999). A longitudinal study of the relation between language and theory of mind development. Developmental Psychology, 35, pp. 1311-1320.

BARON-COHEN, S. (1993). From attention-goal psychology to belief-desire psychology: the development of a theory of mind, and its dysfunction. In S. Baron-Cohen, H. Tager-Flusberg, and D.J.Cohen (Eds.), Understanding Other Minds: Perspectives from Autism (pp.59-82). New York: Oxford University Press.

BARON-COHEN, S, (1994) How to build a baby that can read minds: Cognitive mechanisms in mindreading. Cahiers de Psychologie Cognitive/ Current Psychology of Cognition, 13, pp. 513-552.

BARON-COHEN, S, (1995) Mindblindness: an essay on autism and theory of mind. MIT Press/Bradford Books.

BARON-COHEN, S., LESLIE, A. M., \& FRITH, U. (1985). Does the autistic child have a "theory of mind"? Cognition, 21, pp. 37-46.

BEDNY, A. M., PASCUAL-LEONEA, A., \& SAXE, R. (2009). Growing up blind does not change the neural bases of Theory of Mind. PNAS, 7, 106, 27, pp. 11312-11317

BENSON, G., ABBEDUTO, L., SHORT, K., NUCCIO, J., \& MAAS, F. (1993). Development of a theory of mind in persons with mental retardation: recognizing ignorance and false belief. American Journal on Mental Retardation, 3, pp. 427-433.

BIAŁECKA-PIKUL, M. (2002). Co dzieci wiedza o umyśle i myśleniu. Badania i opis dziecięcej reprezentacji stanów mentalnych. Kraków: Wydawnictwo UJ.

BROWN, J. R., DONELAN-MCCALL, N. \& DUNN, J. (1996) Why Talk about Mental States? The Significance of Children's Conversations with Friends, Siblings, and Mothers, CHILD DEVELOPMENT, 67, 836-849.

CERRUTO, A. (1999).The effects of training on theory of mind tasks with children who are deaf. Dissertation Abstracts International: Section B: The Sciences and Engineering, 60(5-B), p. 2383.

COURTIN, C. (2000). The impact of sign language on the cognitive development of deaf children: the case of theories of mind. Journal of Deaf Studies and Deaf Education, 5(3). 
CUTTING, A. L., \& DUNN, J. (1999). Theory of mind, emotion understanding, language, and family background: Individual differences and interrelations. Child Development, 70, 853-865..

DAHLGREN, S., DAHLGREN-SANDBERG, A., \& HJELMQUIST, E. (2003). The nonspecificity of theory of mind deficits: Evidence from children with communicative disabilities. European Journal of Cognitive Psychology, 15, pp. $129-155$.

DE VILLIERS, J. G., \& DE VILLIERS, P. A. (2000). Linguistic determinism and the understanding of false beliefs. In P. Mitchell \& K. Riggs (Eds.), Children's reasoning about the mind (pp. 191-228). Hove, UK: Psychology Press.

DE VILLIERS, P. A. (2005) The role of language in theory-of-mind development: what deaf children tell us. In Astington, J. W. \& Baird, J. A. (Eds). Why language matters for theory of mind. Oxford: OUP., pp. 266-297.

DE VILLIERS, J. \& PYERS, J. (2002). Complements to cognition: A longitudinal study of the relationship between complex syntax and false belief understanding. Cognitive Development, 17, pp. 1037-1060.

FALKMAN, K. W. (2005). Communicating your way to a Theory of mind. The development of mentalizing skills in children with atypical language development. Sweden: Göteborg University, Department of Psychology.

FLAVELL, J. H., FLAVELL, E. R., \& GREEN, F. L. (1983). Development of the appearance-reality distinction. Cognitive Psychology, 15, pp. 95-120.

FLETCHER, P. C., HAPPE, F., FRITH, U., BAKER, S. C., DOLAN, R. J., FRACKOWIAK, R. S. J. \& FRITH, C. D. (1995). Other minds in the brain: a functional imaging study of "theory of mind" in story comprehension. Cognition, 57(2). pp. 109-128.

GRAY, C. D. \& HOSIE, J. A.(1996). Deafness, Story Understanding, and Theory of Mind Journal of Deaf Studies and Deaf Education, 1:4, pp. 217-233.

JENKINS, J. M., \& ASTINGTON, J. W. (1996). Cognitive factors and family structure associated with theory of mind development in young children. Developmental Psychology, 32, pp. 70-78.

KARMILOFF-SMITH, A., KLIMA, E., BELLUGI, U., GRANT, J. \& BARONCOHEN S. (1995) Is there a social module? Language, face-processing and theory of mind in individuals with Williams syndrome. Journal of Cognitive Neuroscience, 7, pp. 196-208.

LESLIE, A. M. (1987). Pretence and representation: the origins of "theory of mind”. Psychological Review, 94, pp. 412-426. 
LUNDY, J. E. B. (2002). Age and language skills of deaf children in relation to theory of mind development. Journal of Deaf Studies and Deaf Education, 7, pp. 41-56.

MARSCHARK, M. (1993). Psychological development of deaf children. New York: Oxford University Press.

MARSCHARK, M., GREEN, V., HINDMARSH, G., \& WALKER, S. (2000). Understanding theory of mind in children who are deaf. Journal of Child Psychology and Psychiatry, 41, pp. 1067-1073.

MCALPINE, L. M., \& MOORE, C. L. (1995). The development of social understanding in children with visual impairments. Journal of Visual Impairment and Blindness, 89, pp. 349-358.

MILLER, C. A. (2001). False belief understanding in children with specific language impairment. Journal of Communication Disorders, 34 (1/2), pp. 73-86.

MOELLER, P. M., SCHRICK, B. (2006). Relations between maternal input and theory of mind understanding in deaf children. Child development, 77, 3, pp. 751-766.

NELSON, P. B., ADAMSON, L. B., BAKEMAN, R. (2008). Toddlers' joint engagement experience facilitates preschoolers' acquisition of theory of mind. Developmental Science, 11, 6, pp. 847-852.

PERNER, J., LEEKAM, S. R., WIMMER, H. (1987). Three-year-olds' difficulty with false belief: The case for a conceptual deficit. British Journal of Developmental Psychology, 5, pp. 125-137.

PERNER, J., RUFFMAN, T, \& LEEKAM, S. R.(1994). Theory of mind is contagious: You catch it from your sibs. Child Development, 65, pp. 1228-1288.

PETERSON, C. C (2004). Theory-of-mind development in oral deaf children with cochlear implants or conventional hearing aids. Journal of child psychology and psychiatry and allied disciplines. 45, 6, pp. 1096-1106.

PETERSON, C., \& SIEGAL, M. (1995). Deafness, conversation and theory of mind. Journal of Child Psychology \& Psychiatry, 36, pp. 459-474.

PETERSON, C. C., \& SIEGAL, M. (1997). Psychological, physical, and biological thinking in normal, autistic, and deaf children. In H. M. Wellman \& $\mathrm{K}$. Inagaki (Eds.), The emergence of core domains of thought: New directions for child development (Vol. 75, pp. 55-70): San Francisco, CA: Jossey-Bass.

PETERSON, C., \& SIEGAL, M. (1999). Representing inner worlds: Theory of mind in autistic, deaf, and normal hearing children. Psychological Science, 10(2), pp. 126-129. 
PETERSON, C. C., \& SIEGAL, M. (2000). Insights into theory of mind from deafness and autism. Mind and Language, 15, pp. 123-145.

PETERSON, C. C., WELLMAN, H. M., \& LIU, D. (2005). Steps in theory-ofmind development for children with deafness or autism. Child Development, 76(2), pp. 502-517.

PREMACK, D. \& WOODRUFF, G. (1978). Does the chimpanzee have a theory of mind? Behavioral and Brain Sciences., 4, pp. 515-526.

ROWE, A. D., BULLOCK, P. R., POLKEY, C. E., \& MORRIS, R. G. (2001). "Theory of mind" impairments and the relationship to executive functioning following frontal lobe excisions. Brain, 124, pp. 600-616.

RUFFMAN, T., PERNER, J., NAITO, M., PARKIN, L., \& CLEMENTS, W. A. (1998). Older (but not younger) siblings facilitate false belief understanding. Developmental Psychology, 34(1), pp. 161-174.

SALTZMAN, J., STRAUSS, E., HUNTER, M., \& ARCHIBALD, S. (2000). Theory of mind and executive functions in normal human aging and Parkinson Disease. Journal of the International Neuropsychological Society, 6, pp. 781-788.

SAXE, R., \& KANWISHER, N. (2003), People thinking about thinking people: The role of the temporoparietal junction in 'theory of mind'. NeuroImage 19, pp. 1835-1842.

SCHICK, B., DE VILLIERS, P., DE VILLIERS, J. \& HOFFMEISTER, R. (2003). Theory of Mind: Language and Cognition in Deaf Children. The ASHA Leader, 7, pp. 6-14.

SCHICK, B., DE VILLIERS, P., DE VILLIERS, J., \& HOFFMEISTER, R. (2007) Language and Theory of Mind: A Study of Deaf Children. Child Development, 78, 2, pp. 376-396.

SINGLETON, J. L., SUPALLA, S., LITCHFIELD, S., \& SCHLEY, S. (1998). From sign to word: Considering modality constraints in ASL/English bilingual education. Topics in Language Disorders, 18(4), pp. 16-29.

SULLIVAN, K. \& TAGER-FLUSBERG, H. (1999). Second-order belief attribution in Williams syndrome: Intact or impaired? American Journal on Mental Retardation, 104, pp. 523-532.

SVIRSKY, M. A., ROBBINS, A. M., KIRK, K. I., PISONI, D. B., MIYAMOTO, R. T. (2000). Language development in profoundly deaf children with cochlear implants. Psychological Science. 11(2), pp. 153-158.

TAGER-FLUSBERG, H., SULLIVAN, K. (2000). A componential view of theory of mind: evidence from Williams syndrome. Cognition, 76, pp. 59-89. 
TOMASELlO, M., CARPENTER, M., CALL, J., BEHNE, T., MOLL, H. (2005). Understanding and sharing intentions: The origins of cultural cognition. Behavioral And Brain Sciences, 28, pp. 675-735.

WELLMAN, H. M., BARON-COHEN S., CASWELL R., GOMEZ J. C., SWETTENHAM, J., TOYE, E., LAGATTATA K. (2002). Thought Bubbles help children with autism acquire an alternative to a theory of mind. Autism, 6(4), pp. 343-363.

WIMMER, H. \& PERNER, J. (1983). Beliefs about beliefs: Representation and constraining function of wrong beliefs in young children's understanding of perception. Cognition, 13, pp. 103-128.

WOOLFE, T., WANT, S. C. \& SIEGAL, M. (2002) Signposts to development: Theory of mind in deaf children. 73(3). pp. 768-778.

WOOLFE, T., WANT, S. C., SIEGAL, M. (2003). Siblings and Theory of Mind in Deaf Native Signing Children. Journal of Deaf Studies and Deaf Education. 8, 3, pp. 350-347.

ZALEWSKA M. (1998). Dziecko w autoportrecie z zamalowana twarza. Psychologiczne mechanizmy zaburzeń rozwoju tożsamości dziecka głuchego i z opóźnionym rozwojem mowy. Warszawa: Santorski CO.

ZELAZO, P. D., BURACK, J. A., BENEDETTO, E., FRYE, D. (1996). Theory of mind and rule use in individuals with Down's syndrome: a test of the uniqueness and specificity claims. Journal of child psychology and psychiatry, and allied disciplines. 37 (4), pp. 479-84.

Joanna Kossewska,

Department of Psychology,

Pedagogical University of Cracow,

Poland 